\title{
Modifikasi Perilaku Peningkatan Kemampuan Memakai Kaus pada Anak dengan Intellectual Disability Tingkat Sedang
}

\author{
Nafisa Alif Amalia ${ }^{1}$, Luh Surini Yulia Savitri ${ }^{2}$ \\ Fakultas Psikologi Universitas Indonesia \\ e-mail: ${ }^{1}$ nafisa.alif71@ui.ac.id
}

\begin{abstract}
Self-help skills are an important ability to support daily life activities. One of the skills is self-dressing, especially for children which entering puberty. Yet, children with intellectual disability have difficulties in conducting self-help skills. A child with intellectual disability, especially children with moderate-severe intellectual disability, needs support in almost everyday. Eventhough, we have to teaching them to be independent and improves their quality of life. The subject for this research was a boy aged 10 years who were diagnosed with moderate intellectual disability. The purpose is to improve the ability of wearing sleeves independently. The method is single AB design. Technique used is backward chaining, prompting, and positive reinforcement. This research was conducted in 9 sessions, each having 5 trials. The results of this research is behavior modification program of wearing sleeves independently using backward chaining techniques can improve the ability of self-dressing in children with intellectual disability.
\end{abstract}

KEYWORDS Backward chaining, intellectual disability, self-dressing behaviour

CITATION Amalia, N. A., \& Savitri, L. S. Y. (2019). Modifikasi perilaku peningkatan kemampuan memakai kaus pada anak dengan intellectual disability tingkat sedang. Cognicia, 7, (3), 281-294.

Anak dengan intellectual disability (ID) memiliki keterbatasan pada fungsi intelektual dan adaptif (APA, 2013). Untuk menguasai seluruh aktivitas sehari-hariya, anak dengan ID membutuhkan arahan atau pelatihan secara intensif dari orang lain (Wenar \& Kerig, 2006). Menurut Ardic dan Cavkayter (2009), mengajarkan anak dengan intellectual disability mengenai beberapa kemampuan untuk hidup secara mandiri adalah hal yang sangat penting, seperti kemampuan untuk makan, minum, mandi, menyikat gigi, buang air kecil/besar, memakai dan melepaskan pakaian, memakai sepatu, mengancingkan baju, dan kebersihan tubuh. Dari berbagai kemampuan bina diri tersebut, salah satu kemampuan yang paling penting untuk dikuasai oleh anak dengan ID adalah berpakaian. Menurut Westling dan Fox (2009), kemampuan berpakaian adalah hal yang penting untuk anak dengan intellectual disability, terutama jika keterampilan berpakaian yang mereka miliki saat ini tidak sesuai dengan usia kronologis ideal mereka. Lebih lanjut, Marotz dan Allen (2013) menyatakan bahwa sejak berusia 6 tahun, anak seharusnya sudah dapat berpakaian secara mandiri. Kid Sense Child Development (2017) menambahkan bahwa kemampuan untuk berpakaian sudah berkembang sejak anak berusia 1 hingga 2 tahun (membantu dengan memasukkan tangan ke lubang baju), usia 3-4 tahun (berpakaian sendiri 
namun dibantu dalam kancing dan resleting), usia 4-5 tahun (berpakaian dan melepaskan pakaian secara mandiri).

A merupakan seorang klien di Klinik Terpadu Fakultas Psikologi Universitas Indonesia. Berdasarkan hasil pemeriksaan, pemeriksa memperoleh hasil bahwa perilaku yang A tunjukkan sudah memenuhi kriteria dari intellectual disability (ID). Secara lebih spesifik, perilaku yang A tunjukkan berada pada taraf moderate atau sedang. Intellectual disability adalah sebuah gangguan neurodevelopmental yang terjadi pada periode perkembangan dan ditandai dengan adanya defisit pada fungsi intelektual dan adaptif pada domain konseptual, sosial, dan praktikal (APA, 2013). Menurut SAGE Publications (2018), intellectual disability meliputi tiga kriteria, yaitu defisit pada fungsi intelektual, adaptif, dan muncul pada periode perkembangan. Jika dikaitkan dengan masalah yang A alami, perilaku yang A tunjukkan sudah memenuhi ketiga kriteria tersebut dan sudah berdampak pada kehidupannya.

Saat ini, A membutuhkan bantuan secara ekstensif. Menurut Association on Intellectual and Developmental Disabilities/AAIDD (dalam Shree dan Shukla, 2016), bantuan secara ekstensif pada anak ID adalah bantuan yang ditandai dengan keterlibatan orang lain secara rutin (misalnya, setiap hari), setidaknya pada beberapa konteks, seperti sekolah atau rumah. Dukungan tersebut juga tidak dibatasi waktu, yaitu jangka panjang dan selalu intens atau rutin diberikan. Jika dikaitkan dengan masalah yang A alami, saat di rumah, ia selalu dibantu oleh orang tua untuk melakukan aktivitas sehari-hari atau bina diri/self-care. Ia selalu dibantu untuk makan dengan rapi, menyabuni dan membasuh badan saat mandi, memakai dan melepaskan pakaian (kaus, kemeja berkancing, celana, dan membuka atau menutup resleting), serta toileting (membasuh badan saat buang air kecil dan besar). Selain itu, saat di sekolah, A juga didampingi oleh guru secara personal untuk belajar atau menuju ke tempat tertentu, misalnya dari kelasnya menuju ke ruang belajar inklusi. Berbagai dukungan tersebut selalu diberikan orang lain secara rutin dan dalam beberapa konteks (rumah dan sekolah).

A yang saat ini berusia 10 tahun akan masuk ke dalam masa pubertas (prepuberty). Tahap perkembangan tersebut mengharuskan ia sudah dapat berpakaian secara mandiri. Hal tersebut karena pada saat itu, terjadi perubahan bentuk tubuh, yaitu penis yang mulai membesar pada laki-laki dan adanya rambut pada kemaluan (Marotz dan Allen, 2013). Oleh karena itu, melindungi diri dengan mampu berpakaian secara mandiri merupakan hal yang sangat penting bagi A, yaitu pada masa prepuberty. Secara umum, tujuan penelitian ini adalah melatih keterampilan berpakaian pada anak dengan intellectual disability tingkat sedang yang sesuai dengan tahapan berpakaian yang tepat.

APA (2013) menyatakan bahwa kemampuan bina diri anak dengan ID sedang dapat dikembangkan meskipun membutuhkan waktu yang cukup lama. Menurut Swapna dan Sudhir (2016), salah satu cara yang dapat dilakukan untuk mengembangkan fungsi adaptif atau bina diri pada anak dengan intellectual disability adalah modifikasi perilaku. Modifikasi perilaku adalah pendekatan yang fokus pada pengembangan kemampuan adaptif dan perilaku prososial, serta mengurangi perilaku maladaptif dalam kehidupan sehari-hari (Kazdin, 2013). Swapna dan Sudhir (2016) menyatakan bahwa terdapat beberapa teknik yang dapat digunakan dalam modifikasi 
perilaku, seperti positive and negative reinforcement, time-outs, token economy, differential reinforcements, dan chaining. Sejalan dengan hal tersebut, Lee, Muccio, dan Osborne (2014) menambahkan bahwa salah satu bentuk modifikasi perilaku yang dapat dilakukan untuk mengajarkan keterampilan berpakaian pada anak dengan intellectual disability adalah teknik chaining. Chaining adalah tahapan-tahapan intervensi yang terbagi ke dalam tiga metode, yaitu total-task presentation, backward chaining, dan forward chaining (Kazdin, 2013; Martin \& Pear, 2015).

Behavional chaining dapat digunakan untuk mengembangkan keterampilan yang terdiri dari tahapan-tahapan tertentu, yang dapat menjadi kesatuan keterampilan yang cukup kompleks (Tekin-Iftar \& Kurcali-Iftar dalam Aykut, Emecen, Dayi \& Karasu, 2014). Dikarenakan keterampilan berpakaian terdiri dari beberapa tahapan tertentu, pelaksana intervensi memutuskan untuk menggunakan teknik chaining. Secara lebih spesifik, teknik backward chaining adalah teknik chaining yang sering digunakan untuk melatih kemampuan berpakaian pada anak dengan ID. Martin, England, \& England (dalam Martin \& Pear, 2015) menyatakan bahwa teknik backward chaining telah digunakan dalam berbagai program, termasuk mengajarkan berpakaian pada anak dengan keterlambatan perkembangan. Mereka lebih merasa diapresiasi melalui tahapan-tahapan perilaku yang berhasil dilakukan karena biasanya dikombinasikan dengan positive reinforcement (Martin \& Pear, 2015). Oleh karena itu, teknik backward chaining dipilih sebagai teknik yang paling tepat untuk meningkatkan kemampuan berpakaian pada anak dengan ID yang sesuai dengan intervensi ini.

Tidak hanya menggunakan teknik backward chaining, intervensi ini juga menggunakan beberapa teknik lain, yaitu prompting dan positive reinforcement. Prompting mengacu pada antecedents atau hal spesifik yang mendahului sesuatu, yang langsung mengarahkan pada perilaku spesifik tertentu yang diharapkan (Kazdin, 2013). Lebih lanjut, prompts ini dibuat untuk membantu menghasilkan sebuah respon spesifik tertentu. Terdapat tiga jenis prompt yang digunakan dalam intervensi ini, yaitu verbal, gestural/imitative, dan physical/manual guidance. Menurut Kazdin (2013), prompt verbal digunakan untuk memberikan instruksi atau arahan secara verbal, gestural prompt adalah tindakan non-verbal untuk membantu mengarahkan perilaku yang diharapkan, sementara physical/manual guidance prompt adalah bantuan yang langsung mengarahkan fisik, seperti tangan subjek untuk melakukan perilaku tertentu yang diharapkan dalam intervensi. Ketiga jenis prompt tersebut dilakukan untuk mengarahkan perilaku A agar dapat mengikuti tahapan-tahapan berpakaian dengan tepat.

Untuk melengkapi teknik prompting, intervensi ini juga menggunakan positive reinforcement. Sejalan dengan hal tersebut, Kazdin (2013) menyatakan bahwa ketika prompt dapat memicu munculnya perilaku yang diharapkan, konsekuensi berupa positive reinforcement dapat segera diberikan setelah perilaku yang diharapkan muncul. Positive reinforcement adalah sesuatu yang diberikan sebagai penguat perilaku yang diharapkan agar individu tersebut dapat melakukan hal yang sama saat menghadapi situasi tertentu di kemudian hari (Martin \& Pear, 2015). Pada intervensi ini, positive reinforcement yang digunakan adalah consumables reinforcers, activity reinforcer, dan social reinforcers. Menurut Martin dan Pear (2015), consumables reinforcers adalah barangbarang yang dapat dimakan atau diminum, seperti permen, biskuit, dan minuman 
ringan, activity reinforcer adalah memberikan aktivitas yang disukai oleh subjek, sedangkan social reinforcers meliputi pelukan, pujian, senyuman, anggukan, atau setidaknya hal sesederhana pandangan hangat yang menunjukkan kasih sayang. Pada intervensi ini, consumables dan activity reinforcers diberikan di setiap akhir sesi intervensi (saat sesi intervensi berakhir), sedangkan social reinforcement diberikan kapan pun subjek berhasil melakukan tahapan berpakaian yang diharapkan selama berlangsungnya sesi.

\section{METODE}

Penelitian ini merupakan penelitian kuantitatif dengan single case AB design. Penelitian ini menerapkan intervensi modifikasi perilaku untuk meningkatkan kemampuan memakai kaus berlengan. Setelah dilakukan proses asesmen, terdapat beberapa hal yang memengaruhi kemampuan A dalam memakai kaus berlengan, yaitu:

Tabel 1. Functional Behavioral Assessment (FBA)

\begin{tabular}{|c|c|c|}
\hline Antecedent & Behavior & Consequences \\
\hline $\begin{array}{l}\text { Saat ingin memakai baju: } \\
\text { - A selalu dibantu oleh ibu untuk } \\
\text { memakai baju } \\
\text { - Orang tua tidak mengetahui } \\
\text { bagaimana cara untuk } \\
\text { mengajarkan A memakai baju } \\
\text { secara mandiri }\end{array}$ & $\begin{array}{l}\text { A belum mampu untuk } \\
\text { memakai baju secara } \\
\text { mandiri }\end{array}$ & $\begin{array}{ll}\text { - A tidak dapat } \\
\text { memakai baju secara } \\
\text { mandiri } \\
\text { - Orang tua selalu } \\
\text { membantu A untuk } \\
\text { memakai baju }\end{array}$ \\
\hline
\end{tabular}

Berdasarkan tabel di atas, terdapat beberapa hal yang memengaruhi kemampuan A dalam memakai kaus berlengan saat ini. Pertama, A selalu dibantu oleh ibu untuk memakai kaus, sehingga ia belum mampu untuk memakai kaus secara mandiri. Kedua, orang tua tidak mengetahui bagaimana cara untuk mengajarkan A memakai kaus secara mandiri, hingga ibu selalu membantu A untuk memakai kaus.

Fungsi dari perilaku ketidakmampuan memakai kaus berlengan oleh A disebabkan karena intellectucal disability. Intellectual disability yang A alami ditunjukkan dengan adanya keterbatasan pada fungsi intelektual dan adaptif. Lebih lanjut, keterbatasan A dalam perilaku adaptif atau kemampuan bina diri, menyebabkannya belum mampu untuk berpakaian secara mandiri. Ia masih membutuhkan bantuan dan arahan dari orang lain. Sejalan dengan hal tersebut, kemampuan bina diri anak dengan intellectual disability sedang dapat dikembangkan meskipun membutuhkan waktu dan pelatihan.

Perilaku yang menjadi target dalam intervensi ini adalah perilaku defisit memakai kaus berlengan secara mandiri. Pelaksana intervensi menggunakan acuan tahapan berpakaian berdasarkan Turner et al. (2001), yaitu:

1. Tarik/masukkan baju di atas kepala

2. Dorong lengan kanan ke atas melalui lubang lengan kanan baju

3. Dorong lengan kiri ke atas melalui lubang lengan kiri baju 
4. Tarik baju hingga ke pinggang

Pada program intervensi ini, baju yang pelaksana intervensi gunakan adalah kaus berlengan, tanpa kancing. Untuk membedakan bagian depan dan belakang kaus, terdapat gambar pada bagian depan yang akan mempermudah anak untuk membedakan bagian kaus. Pelaksana intervensi menggunakan kaus berlengan dalam intervensi ini karena A sering menggunakan kaus berlengan dalam kesehariannya.

Berdasarkan acuan dari Turner et al. (2001), definisi operasional perilaku yang ingin ditingkatkan dalam program intervensi ini adalah kemampuan memakai kaus berlengan yang terdapat gambar pada bagian depan kaus dan bentuknya berlengan (tanpa kancing). Perilaku dimulai dari menarik kaus dari atas kepala, memasukkan lengan kanan ke lubang lengan kanan kaus, lalu memasukkan lengan kiri ke lubang lengan kiri kaus, dan terakhir yaitu menarik kaus hingga ke pinggang (menutupi bagian perut).

Penelitian ini sudah memenuhi standar disiplin ilmu psikologi, yaitu Kode Etik Riset Universitas Indonesia yang terlampir dalam Surat Keterangan Lolos Kaji Etik. Selain itu, peneliti juga memberikan surat persetujuan sebagai respondengan atau informed consent. Secara keseluruhan, pelaksanaan intervensi ini dibagi menjadi tiga tahap, yaitu pengambilan data awal (baseline), tahap pemberian intervensi, dan pengambilan data akhir (follow-up).

Tahap baseline ini dilakukan dengan tujuan untuk mengidentifikasi kemampuan awal subjek untuk memakai kaus berlengan secara mandiri sebelum diberikan intervensi. Selain itu, tahap ini juga berguna untuk melihat beberapa faktor yang dapat memengaruhi keberhasilan proses intervensi, seperti faktor lingkungan. Tahap baseline ini dilakukan di rumah A pada pukul 15.30-16.30, yaitu waktu setelah A mandi sore. Sebelum melakukan pengambilan baseline, A sudah memakai kaus dalam terlebih dahulu. Hal tersebut dilakukan untuk memberikan kenyamanan, karena A sudah menuju masa pubertas (menghindari rasa malu yang mungkin akan ia alami) dan pelaksana intervensi yang berjenis kelamin perempuan. Pihak yang melakukan pengukuran baseline adalah pelaksana intervensi yang didampingi oleh ibu. Baseline dilakukan selama dua sesi (dua hari). Setiap sesi terdiri dari 5 percobaan. Dengan menggunakan metode tersebut, pelaksana intervensi akan melakukan observasi dalam satu periode waktu tertentu dan melakukan pencatatan pada setiap target perilaku yang muncul pada periode waktu tersebut (Martin \& Pear, 2015).

Berikut ini merupakan hasil dari pengambilan baseline:

\section{Grafik Penguasaan Kemampuan}

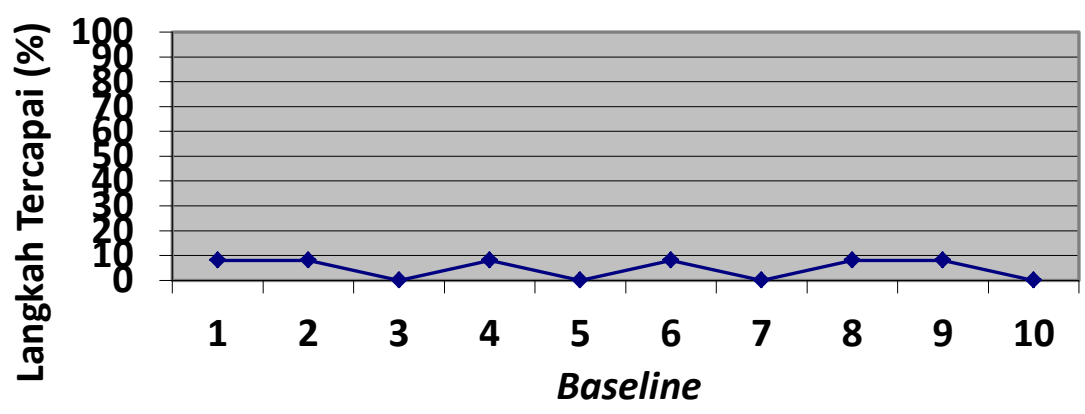


Grafik 1. Penguasaan Kemampuan Tahap Baseline

Tabel 2. Penggunaan Prompt/bantuan pada Tahap Baseline

\begin{tabular}{|c|c|c|c|c|c|c|c|c|c|c|c|}
\hline \multirow{2}{*}{ Langkah } & \multirow{2}{*}{ Respon } & \multicolumn{10}{|c|}{ Baseline } \\
\hline & & 1 & 2 & 3 & 4 & 5 & 6 & 7 & 8 & 9 & 10 \\
\hline 1 & $\begin{array}{l}\text { Menarik kaus dari atas } \\
\text { kepala }\end{array}$ & 1 & 0 & 0 & 0 & 0 & 1 & 0 & 0 & 0 & 0 \\
\hline 2 & $\begin{array}{l}\text { Memasukkan lengan } \\
\text { kanan ke lubang lengan } \\
\text { kanan kaus }\end{array}$ & 0 & 0 & 0 & 1 & 0 & 0 & 0 & 0 & 0 & 0 \\
\hline 3 & $\begin{array}{ll}\text { Memasukkan lengan } \\
\text { kiri ke lubang } \\
\text { kiri kaus }\end{array}$ & 0 & 0 & 0 & 0 & 0 & 0 & 0 & 0 & 0 & 0 \\
\hline 4 & $\begin{array}{l}\text { Menarik kaus hingga ke } \\
\text { pinggang }\end{array}$ & 0 & 1 & 0 & 0 & 0 & 0 & 0 & 1 & 1 & 0 \\
\hline Nilai per & entase keberhasilan (\%) & 8 & 8 & 0 & 8 & 0 & 8 & 0 & 8 & 8 & $\mathbf{0}$ \\
\hline
\end{tabular}

Keterangan:

$3 \rightarrow$ tanpa prompt

$1 \rightarrow$ gestural/imitative prompt

$2 \rightarrow$ verbal prompt

$0 \rightarrow$ physical/manual guidance

Hasil persentase pada tahap baseline ini menunjukkan bahwa kemampuan A berkisar antara $0 \%$ hingga $8 \%$. Berdasarkan hasil pengukuran baseline, diketahui bahwa subjek masih membutuhkan arahan dan bantuan dari orang lain untuk berpakaian (memakai kaus berlengan) dengan perintah verbal, contoh gerakan, dan bantuan fisik (mengarahkan tangan subjek untuk melakukan suatu hal tertentu). Selain itu, hasil pengukuran baseline ini juga menunjukkan bahwa A masih kesulitan untuk mencari lubang baju dan memasukkan tangan kanan atau kiri ke lubang baju dengan tepat. Terkadang, ia memasukkan tangan kanan ke lubang kiri baju, begitu pun sebaliknya. A juga masih kesulitan untuk menarik kaus ke pinggang. Ia membutuhkan waktu cukup lama dan bantuan dari orang lain untuk menurunkan baju dan membetulkan lipatan-lipatan baju, terutama pada baju bagian belakang.

Tahap intervensi ini dilakukan di rumah A pada pukul 15.30-16.30, yaitu waktu setelah A mandi sore. Sebelum melakukan sesi, A sudah memakai kaus dalam terlebih dahulu. Hal tersebut dilakukan untuk memberikan kenyamanan, karena A sudah menuju masa pubertas (menghindari rasa malu yang mungkin akan ia alami) dan pelaksana intervensi yang berjenis kelamin perempuan. Intervensi diberikan selama 5 sesi dengan 5 kali percobaan. Hal ini bermaksud untuk melihat konsistensi dari perilaku yang akan diintervensi. Setiap percobaan memiliki target peningkatan kemampuan yang berbeda.

Pada tahap intervensi, semua teknik penelitian diberikan, yaitu backward chaining, prompting, serta positive reinforcement. Berikut ini adalah penjabarannya:

1. Melalui backward chaining, kemampuan A dalam memakai kaus berlengan akan dimulai dari tahapan terakhir, terus berlanjut hingga tahap paling awal. Setiap respon menghasilkan sebuah stimulus yang akan memengaruhi stimulus 
diskriminatif $\left(\mathrm{S}^{\mathrm{D}}\right)$ untuk respon berikutnya, hingga seluruh rangkaian tahapan tersebut selesai dan diberikan reinforcement untuk memperkuat respon terakhir (Miltenberger, 2012).

2. Pada prompting, bantuan yang akan diberikan berupa bantuan secara verbal, gestural/imitative, dan physical/manual guidance. Berikut ini adalah penjabarannya:

- Modelling prompting diberikan pada tahap awal (sebelum masuk ke tahap intervensi) dengan tujuan untuk memandu subjek berpakaian dengan langkah-langkah yang tepat melalui bentuk video. Hal tersebut didasarkan karena subjek merupakan anak dengan intellectual disability. Martin \& Pear (2015) menyatakan bahwa pada beberapa kasus, seperti anak dengan intellectual disability sebaiknya diberikan suatu model atau contoh seluruh rangkaian yang akan diajarkan.

- Gestural/imitative prompting diberikan melalui gerakan tubuh dari orang lain yang menandakan bahwa A menunjukkan perilaku yang sesuai/tepat, seperti anggukan atau gerakan. Sebagai contoh, pelaksana intervensi menunjuk lubang kaus bagian kanan agar A memasukkan tangan kanannya ke lubang tersebut.

- Physical/manual guidance diberikan dengan memandu secara fisik $\rightarrow$ langsung memegang tangan A dan memasukkan tangan kanannya ke lubang kaus kanan.

- Verbal prompting diberikan melalui instruksi secara verbal. Sebagai contoh: "masukkan tangan kanannya" atau "turunkan bajunya".

3. Positive reinforcement diberikan ketika A berhasil melakukan perilaku yang diharapkan, terdiri dari social, consumables dan activity reinforcers. Berikut adalah penjabarannya secara spesifik:

- Social reinforcement diberikan ketika A dapat melakukan setiap percobaan dengan tepat, berupa tepuk tangan, senyuman, dan pujian. Pujian yang dapat diberikan, seperti "A hebat!" atau "ayo A pasti bisa".

- Consumables reinforcers diberikan di akhir sesi saat A berhasil menyelesaikan target perilaku, berupa barang yang A sukai, baik handphone atau makanan dan minuman. Pelaksana intervensi akan meminta orang tua untuk mengurutkan daftar makanan dan minuman berdasarkan tingkat kesukaan A.

- Activity reinforcer diberikan di akhir sesi saat A berhasil menyelesaikan target perilaku, berupa pemberian aktivitas yang A sukai, yaitu menonton youtube di handphone atau menonton televisi.

Tabel 3. Daftar Activity Reinforcer Berdasarkan Tingkat Kesukaan A:

\begin{tabular}{cc}
\hline Urutan & Jenis Aktivitas \\
\hline 1 & Menonton youtube di handphone \\
\hline 2 & Menonton televisi \\
\hline
\end{tabular}

Untuk melaksanakan intevensi ini, pelaksana intervensi menggunakan metode pencatatan data continuous recording. Dengan menggunakan metode tersebut, 
pelaksana intervensi akan melakukan observasi dalam satu periode waktu tertentu dan melakukan pencatatan pada setiap target perilaku yang muncul pada periode waktu tersebut (Martin \& Pear, 2015).

Tabel 4. Tahapan Pemberian Prompt (pada satu kali percobaan):

\begin{tabular}{|c|c|c|}
\hline Urutan & Target Perilaku & Aktivitas \\
\hline Langkah 1 & Tahap 4 & $\begin{array}{l}\text { Pengadministrasian prompt dilakukan untuk } \\
\text { tahap } 1 \text { sampai } 3 \text {. Pada tahap } 4 \text {, A harus } \\
\text { melakukannya sendiri. }\end{array}$ \\
\hline Langkah 2 & Tahap 4 dan 3 & $\begin{array}{l}\text { Pengadministrasian prompt dilakukan pada } \\
\text { tahap } 1 \text { sampai } 2 \text {. Pada tahap } 3 \text { dan } 4 \text {, A } \\
\text { harus melakukannya secara mandiri. }\end{array}$ \\
\hline Langkah 3 & Tahap 4, 3, dan 2 & $\begin{array}{l}\text { Pengadministrasian prompt dilakukan hanya } \\
\text { pada tahap } 1 \text {. Pada tahap sisanya }(2,3 \text {, dan } \\
4 \text { ), A harus melakukannya secara mandiri. }\end{array}$ \\
\hline Langkah 4 & Tahap 4, 3, 2, dan 1 & $\begin{array}{l}\text { Prompt atau bantuan tidak diberikan lagi. A } \\
\text { harus melakukan setiap langkah ( } 1 \text { sampai } 4) \\
\text { secara mandiri, tanpa bantuan. }\end{array}$ \\
\hline
\end{tabular}

Berikut ini adalah urutan prompt yang diberikan:
$3 \rightarrow$ tanpa prompt
$1 \rightarrow$ gestural/imitative prompt
$2 \rightarrow$ verbal prompt
$0 \rightarrow$ physical/manual guidance

Keterangan:

- Sesi dikatakan gagal jika dalam 5 kali percobaan (satu sesi), anak tetap membutuhkan semua prompt (verbal, gestural/imitative, dan physical/manual).

- Sesi dikatakatan berhasil jika dalam satu sesi (5 kali percobaan), terdapat penurunan prompt yang diberikan, yaitu tidak ada prompt atau minimal diberikan verbal prompt.

- Di akhir intervensi, intervensi ini akan dianggap berhasil jika terdapat peningkatan kemampuan/penguasaan berpakaian sebesar 60\% (di akhir sesi intervensi). Hal tersebut dilakukan untuk melihat konsistensi dari peningkatan kemampuan memakai kaus berlengan yang dilakukan di dalam intervensi ini.

Program intervensi ini dikatakan berhasil jika subjek penelitian menunjukkan peningkatan pada kemampuan memakai kaus berlengan tanpa kancing yang sesuai empat tahapan yang tepat, yaitu menarik kaus dari atas kepala, memasukkan lengan kanan ke lubang lengan kanan kaus, memasukkan lengan kiri ke lubang lengan kiri kaus, dan menarik kaus hingga ke pinggang. Peningkatan yang ditargetkan sebesar perolehan persentase sebesar $60 \%$ dalam 5 kali intervensi. Hal ini ditujukan untuk melihat konsistensi dari peningkatan kemampuan berpakaian. Lebih lanjut, program ini dikatakan berhasil jika A dapat memakai kaus berlengan secara mandiri, tanpa bantuan atau minimal dengan bantuan verbal. Untuk menentukan keberhasilan program intervensi, pelaksana intervensi melakukan perbandingan catatan 
kemampuan memakai kaus pada sebelum (baseline) dan sesudah (follow-up) diberikan program modifikasi perilaku.

Tahap follow-up ini dilakukan 2 minggu setelah program intervensi dilaksanakan. Tahap ini dilakukan di rumah A pada pukul 15.30-16.30, yaitu waktu setelah A mandi sore. Sebelum melakukan sesi, A sudah memakai kaus dalam terlebih dahulu. Tahap follow-up ini diberikan untuk menentukan keberhasilan dari program intervensi yang dilakukan. Pelaksana intervensi akan melakukan dua sesi atau dua hari follow-up. Setiap sesi follow-up terdiri dari lima kali percobaan. Tahap ini dilakukan untuk melihat apakah perilaku memakai kaus berlengan dapat bertahan meskipun pelaksana intervensi tidak terlihat secara langsung dan tidak adanya consumable atau activity reinforcer yang diberikan.

Tahap follow-up ini dilakukan 3 minggu setelah pelaksanaan intervensi di sesi terakhir. Pelaksanaan follow-up ini mundur 1 minggu dari jadwal yang sudah direncanakan sebelumnya, dikarenakan subjek yang berhalangan karena sedang libur sekolah dan tidak berada di rumah. Sementara itu, hasil persentase pada tahap followup ini menunjukkan bahwa kemampuan A berkisar antara 92\% hingga 100\%, dengan hampir semua sesi follow-up berada pada skor 100\%. Berdasarkan hasil pengukuran follow-up, diketahui bahwa subjek sudah dapat memakai kaus berlengan secara mandiri dengan cukup konsisten. Dari dua sesi follow-up (10 kali percobaan), A mampu memakai kaus secara mandiri sebanyak 9 kali percobaan. Hanya saja, pada satu percobaan follow-up, subjek membutuhkan bantuan verbal dengan kalimat "ayo, turunkan bajunya", pada tahap keempat, yaitu menarik kaus hingga ke pinggang. Hal tersebut karena fokusnya sedang teralihkan untuk mengambil handphone di kamar dan segera ingin meninggalkan tempat pelaksaan intervensi. Pada tahap follow-up ini, A terlihat lancar dan mampu mempertahankan kemampuan sejak sesi-sesi terakhir intervensi dalam melakukan tahapan memakai kaus berlengan dengan tepat secara mandiri.

\section{HASIL}

Program modifikasi perilaku ini dilakukan sebanyak 5 sesi (sesuai dengan langkah atau tahapan memakai kaus berlengan ditambah 1 sesi tambahan) dengan 5 percobaan di setiap sesi. Program ini dilaksanakan pada tanggal 10-16 April 2019 di rumah klien. Waktu pelaksanaan program ini adalah pukul 06.15-07.00 dan 19.3020.30. Waktu ini berbeda dengan waktu yang direncanakan sebelumnya karena pada saat pelaksanaan intervensi dimulai (setelah sesi baseline), ibu subjek mulai bekerja sejak pukul 08.00-17.00 (tiba di rumah pukul 19.15). Oleh karena itu, pelaksanaan intervensi dapat dimulai pagi hari sebelum ibu berangkat bekerja dan malam hari setelah ibu pulang kerja. Pada waktu-waktu tersebut, subjek sedang dalam kondisi yang memungkinkan untuk melaksanakan intervensi.

Berikut ini adalah grafik penguasaan kemampuan berpakaian A pada tahap baseline, intervensi, dan follow-up: 


\section{Grafik Penguasaan Kemampuan}

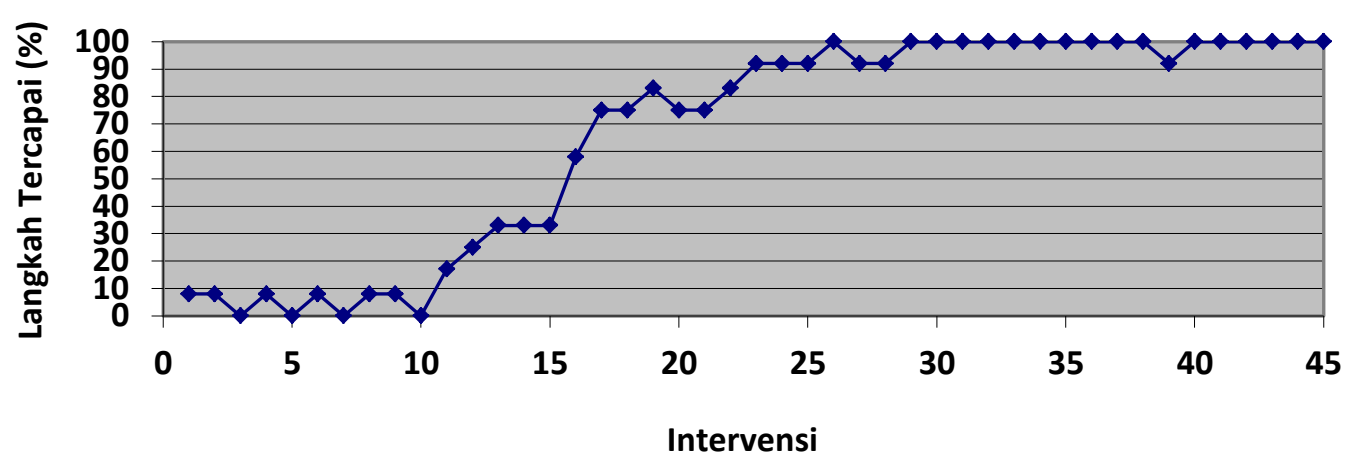

Grafik 2. Penguasaan Kemampuan Tahap Intervensi

Berdasarkan grafik penguasaan kemampuan berpakaian sejak tahap baseline hingga follow-up, diketahui bahwa terjadi peningkatan penguasaan kemampuan memakai kaus berlengan pada tahap intervensi dari $0 \%$ menjadi $100 \%$. Nilai tersebut dapat diartikan bahwa subjek dapat melakukan perilaku memakai kaus berlengan secara mandiri, tanpa bantuan orang lain. Terjadi perubahan kemampuan dari tahap baseline hingga follow-up, mulai dari pemberian bantuan yang berkurang, mempu mencari lubang baju dan memasukkan tangan dengan tepat, dan lancar dalam menarik kaus hingga ke pinggang pada tahap terakhir. Sejalan dengan hal tersebut, terlihat bahwa terjadi penurunan pemberian prompt. Hal ini berdasarkan dengan semakin tinggi nilai penguasaan kemampuan berpakaian pada setiap percobaan, maka terjadi penurunan penggunaan prompt atau bantuan yang diberikan kepada subjek.

Berikut ini adalah grafik pengunaan prompt tahap baseline, intervensi, dan followup:

\section{Grafik Penguasaan Kemampuan}

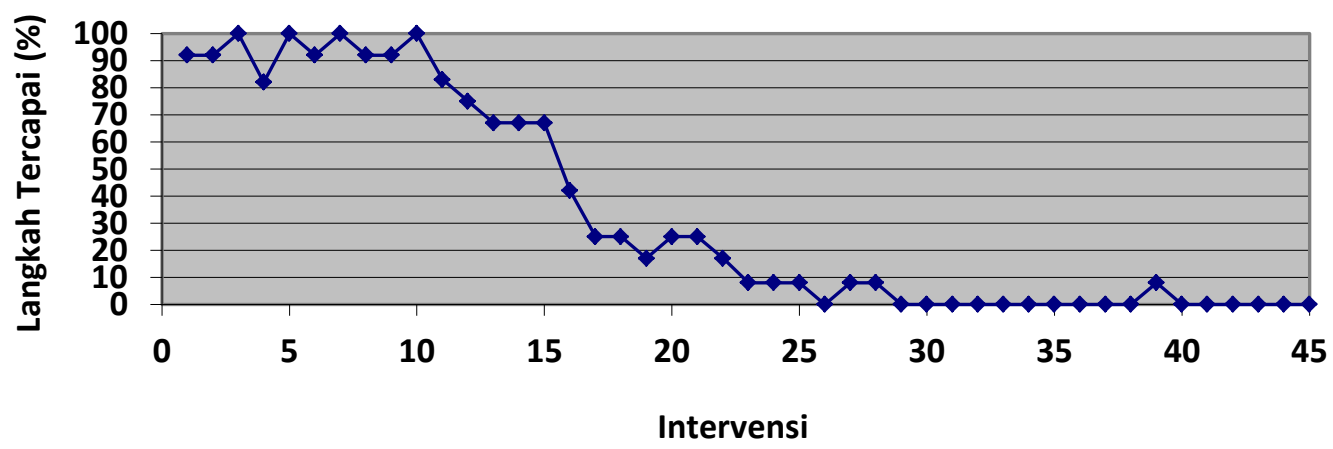

Grafik 3. Penggunaan Prompt

Pada beberapa percobaan pertama di tahap intervensi, subjek masih membutuhkan bantuan atau prompt berupa arahan langsung secara fisik, misalnya 
dengan mengarahkan tangan subjek masuk ke dalam lubang kaus tangan kanan atau kiri. Selain itu, subjek beberapa kali membutuhkan bantuan untuk menurunkan kaus yang terlipat dengan tepat hingga ke pinggang. Tidak hanya itu, pada awal-awal sesi intervensi ini, A juga sering mendekati dan meminta bantuan ibu untuk memakai kaus ini, namun ibu selalu menolaknya dan meminta A memakainya sendiri. Setelah itu, pada beberapa percobaan setelahnya, subjek tidak membutuhkan banyak bantuan. Bantuan yang diberikan misalnya berupa gerakan tubuh (menunjuk bagian tertentu) dan bantuan secara verbal, misalnya "A belakang bajunya belum" atau "turunkan bajunya ya". Kemudian, pada beberapa percobaan di sesi intervensi terakhir, A sudah mulai dapat berpakaian secara mandiri. Ia mulai lancar dan tepat dalam melakukan tahapan memakai kaus berlengan. A juga tidak lagi mendekati dan meminta bantuan ibu untuk memakaikannya kaus berlengan.

\section{DISKUSI}

Terdapat beberapa faktor yang memengaruhi keefektifan program intervensi ini, yaitu:

1. Teknik intervensi

Teknik yang digunakan dalam intervensi ini adalah backward chaining. Menurut beberapa penelitian, teknik ini efektif untuk mengajarkan anak berpakaian secara mandiri, terutama pada anak dengan intellectual disability. Sejalan dengan hal tersebut, Lee, Muccio, dan Osborne (2014) menyatakan bahwa salah satu bentuk modifikasi perilaku yang dapat dilakukan untuk mengajarkan keterampilan berpakaian pada anak dengan intellectual disability adalah teknik backward chaining. Martin, England, \& England (dalam Martin \& Pear, 2015) menyatakan bahwa teknik backward chaining telah digunakan dalam berbagai program, termasuk mengajarkan berpakaian pada anak dengan keterlambatan perkembangan. Mereka akan lebih merasa diapresiasi melalui tahapan-tahapan perilaku yang berhasil dilakukan karena biasanya dikombinasikan dengan positive reinforcement (Martin \& Pear, 2015). Pada A, ia terlihat sangat senang setiap mampu melalui tahapan berpakaian karena diapresiasi oleh pelaksana intervensi atau ibu. Oleh karena itu, teknik backward chaining ini berhasil diberikan untuk meningkatkan kemampuan berpakaian A.

2. Reinforcement

Penggunaan reinforcement pada intervensi ini dianggap efektif untuk memperkuat perilaku yang diharapkan pada subjek. Pada intervensi ini, pelaksana intervensi menggunakan reinforce berupa social reinforcement dengan memberikan senyuman dan pujian, seperti "A hebat!" atau "ayo A pasti bisa". Sejalan dengan hal tersebut, Martin \& Pear (2015) menyatakan bahwa ketika kita mengajarkan suatu perilaku kepada anak dengan intellectual disability atau anak yang lebih kecil, sebaiknya kita segera memberikan pujian kepada mereka jika mereka berhasil menyelesaikan tugas atau tahap yang diharapkan pada setiap percobaan. Selain itu, selama sesi intervensi, pelaksana intervensi juga memberikan activity reinforcers berupa aktivitas yang A sukai, baik menonton youtube di handphone atau pun menonton televisi yang diberikan setelah sesi intervensi jika A mampu menyelesaikan sesi dengan baik. Sejalan dengan hal 
tersebut, Martin \& Pear (2015) menyatakan bahwa reinforcement utama (seperti sesuatu yang dapat dimakan) juga sering diinginkan oleh anak-anak ID, namun bergantung pada penyelesaian keberhasilan setiap tahap perilaku yang diharapkan.

\section{Modelling prompting}

Pelaksana intervensi memberikan modelling prompting pada tahap awal (sebelum pelaksanaan intervensi) dengan tujuan untuk memandu subjek berpakaian dengan langkah-langkah yang tepat melalui bentuk video. Hal tersebut didasarkan karena A merupakan anak dengan intellectual disability. Martin \& Pear (2015) menyatakan bahwa pada beberapa kasus, seperti anak dengan intellectual disability atau anak yang lebih kecil sebaiknya diberikan suatu model atau contoh seluruh rangkaian yang akan diajarkan sambil dijelaskan secara verbal pada setiap langkahnya. Selain itu, pemberian prompt melalui bentuk video dikarenakan A yang sangat senang menonton video di youtube. Saat diberikan video ini pun, A terlihat sangat senang dan memperhatikan video yang diberikan. Pemberian video ini diharapkan dapat menarik minat subjek untuk mencoba berpakaian secara mandiri. Pemberian modelling prompting ini dapat membantu subjek untuk memahami tahap-tahap memakai kaus berlengan dengan tepat.

Di sisi lain, pada grafik penguasaan kemampuan berpakaian dari tahap baseline, intervensi, dan follow-up, terlihat bahwa ada bagian grafik yang fluktuatif, walaupun hanya sedikit dan tidak memengaruhi peningkatan kemampuan subjek. Beberapa hal dapat menjadi penyebab dari adanya kemampuan yang fluktuatif, yaitu:

1. A merupakan anak dengan intellectual disability tingkat sedang. Usia mental setara dengan anak berusia 3 tahun 3 bulan. Dengan kemampuan kognitif yang terbatas, hal tersebut memengaruhi proses belajarnya yang lebih lama dan fluktuatif. Sementara itu, kemampuan kognitifnya juga membuat A kurang fokus dalam melakukan sesuatu.

2. Faktor lingkungan selama proses intervensi yang kurang kondusif. Meskipun pelaksana intervensi sudah berusaha untuk mengontrol lingkungan, mulai dari tempat dan siapa saja yang sebaiknya ada di dalam sesi intervensi, namun ada hal yang tidak terduga yaitu kehadiran saudara A ke ruangan dan berbicara kepada A.

Walaupun ada beberapa keterbatasan dari program ini, namun kemampuan A dalam memakai kaus berlengan sudah menunjukkan adanya kualitas peningkatan kemampuan yang baik. Hal tersebut ditunjukkan dengan A yang mampu memakai kaus berlengan secara mandiri (tanpa bantuan orang lain) di akhir sesi intervensi walaupun ia merupakan anak dengan intellectual disability tingkat sedang. Dengan keterbatasan kognitif yang dimilikinya, peningkatan kemampuan berpakaian A menunjukkan hasil yang sangat baik. Sementara itu, program intervensi ini juga dapat diterapkan di kehidupan A sehari-hari atau digeneralisasi. Hal tersebut karena reinforcement yang berupa social (pujian), consumables (barang/makanan), dan activity (menonton youtube di handphone dan menonton televisi) tidak bertahan atau tidak perlu 
diberikan saat follow-up. Dengan demikian, perilaku A dalam memakai kaus tidak tergantung pada suatu hal, yaitu reinforcement.

\section{SIMPULAN DAN IMPLIKASI}

Berdasarkan seluruh data yang didapatkan dari tahap baseline, intervensi, dan follow-up, dapat disimpulkan bahwa program modifikasi perilaku memakai kaus berlengan secara mandiri dengan menggunakan teknik backward chaining efektif diberikan pada anak dengan intellectual disability tahap moderate/sedang. Secara keseluruhan, terdapat peningkatan kemampuan memakai kaus berlengan secara mandiri.

\section{Saran untuk Orang Tua}

Berikut ini adalah beberapa saran dalam mempertahankan perilaku memakai kaus berlengan yang dapat diterapkan orang tua kepada A, yaitu orang tua sebaiknya memberikan kesempatan kepada A untuk memakai kaus secara mandiri. Usahakan untuk tidak langsung memakaikannya kaus atau memberikan bantuan, kecuali bantuan verbal. Selain itu, saat A meminta bantuan, orang tua harus menolaknya dengan cara menyemangati A bahwa ia dapat berpakaian secara mandiri.

\section{Saran untuk Praktisi}

Saran yang dapat diperhatikan oleh praktisi lain untuk menerapkan program modifikasi perilaku dengan teknik backward chaining pada anak dengan ID, yaitu praktisi harus mengkondisikan tempat dan waktu intervensi agar proses intervensi dapat berlangsung dengan baik tanpa terganggu kondisi lingkungan. Sebelum memulai sesi intervensi, praktisi sebaiknya menyampaikan kepada orang tua, siapa saja yang boleh berada di ruangan selama proses intervensi berlangsung.

\section{REFERENSI}

American Psychiatric Association. (2013). Diagnostic and statistical manual of mental disorders, 5.

Ardic, A., \& Cavkayter. (2009). the Effectiveness of Modified Intensive Toliet Training Method on The Teaching Toileting Skill to Children With Autism. Turkey: Anadolus University, Faculty of Education Turkey.

Aykut, C., Emecen, D.D., Dayi, E., \& Karasu, N. (2014). Teaching chained tasks to students with intellectual disabilities by using video prompting in small group instruction. Educational Sciences: Theory \& Practice, 14(3), 1082-1087

Kazdin, A.E. (2013). Behavior modification in applied settings (7th ed.).Illinois: Waveland Press.

Kid Sense Child Development. (2017). Self care developmental chart. Diunduh dari: childdevelopment.com.au.

Lee, S. C., Muccio, B. E., \& Osborne, N. L. (2009). The effect of chaining techniques on dressing skills of children with moderate mental retardation: A single-subject design study. Journal of Occupational Therapy, Schools, \& Early Intervention, 2(3-4), 178-192.

Marotz, L. R., \& Allen, K. E. (2013). Developmental profiles: Pre-birth through adolescence. Nelson Education.

Martin, G., \& Pear, J. J. (2015). Behavior modification: What it is and how to do it. Psychology Press. 
Miltenberger, R. G. (2012). Behavior Modification, Principles and Procedures . USA: Cengage Learning.

SAGE Publications. (2018). Chapter 5 Intellectual disability and developmental disorders.

Shree, A., \& Shukla, P. C. (2016). Intellectual disability: Definition, classification, causes and characteristics. Learning Community: An International Journal of Educational and Social Development, 7(1), 9.

Swapna, \& M.A.Sudhir. (2016). Behaviour Modification for Intellectually Disabled Students. Journal Of Humanities And Social Science, Volume 21, Issue 2, Ver. VIII PP 35-38.

Turner, L., Lammi, B., Friesen, K., \& Phelan, N. (2001). Your child dressing's workbook. Canada Child Centre for Childhood Disability Research.: https://www.cshsurrey.co.uk/ourservices/service-children/occupational-therapy.

Wenar, C., \& Kerig, P. (2006). Developmental psychopathology : from infancy through adolescence . London: McGraw-Hill.

Westling, D. L., \& Fox, L. L. (2009). Teaching Students with Severe Disabilities , (4th Ed.). South Florida, FL: Pearson. 